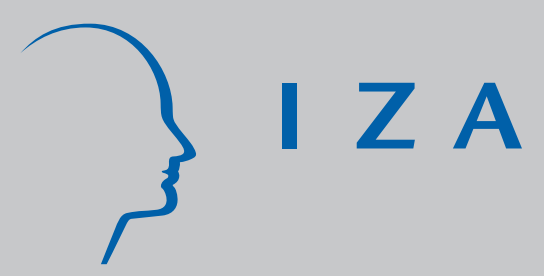

IZA DP No. 620

Public Policy and the Labor Market Adjustment of New Immigrants to Australia

Deborah A. Cobb-Clark

October 2002 


\title{
Public Policy and the Labor Market Adjustment of New Immigrants to Australia
}

\author{
Deborah A. Cobb-Clark \\ SPEAR Centre, RSSS, Australian National University \\ and IZA Bonn
}

Discussion Paper No. 620

October 2002

\author{
IZA \\ P.O. Box 7240 \\ D-53072 Bonn \\ Germany \\ Tel.: +49-228-3894-0 \\ Fax: +49-228-3894-210 \\ Email: iza@iza.org
}

This Discussion Paper is issued within the framework of IZA's research area Mobility and Flexibility of Labor. Any opinions expressed here are those of the author(s) and not those of the institute. Research disseminated by IZA may include views on policy, but the institute itself takes no institutional policy positions.

The Institute for the Study of Labor (IZA) in Bonn is a local and virtual international research center and a place of communication between science, politics and business. IZA is an independent, nonprofit limited liability company (Gesellschaft mit beschränkter Haftung) supported by the Deutsche Post AG. The center is associated with the University of Bonn and offers a stimulating research environment through its research networks, research support, and visitors and doctoral programs. IZA engages in (i) original and internationally competitive research in all fields of labor economics, (ii) development of policy concepts, and (iii) dissemination of research results and concepts to the interested public. The current research program deals with (1) mobility and flexibility of labor, (2) internationalization of labor markets, (3) welfare state and labor market, (4) labor markets in transition countries, (5) the future of labor, (6) evaluation of labor market policies and projects and (7) general labor economics.

IZA Discussion Papers often represent preliminary work and are circulated to encourage discussion. Citation of such a paper should account for its provisional character. A revised version may be available on the IZA website (www.iza.org) or directly from the author. 


\section{ABSTRACT \\ Public Policy and the Labor Market Adjustment of New Immigrants to Australia}

Two separate cohorts of immigrants to Australia are compared in order to assess the potential role of immigrant selection criteria, labor market conditions, and income-support policy in facilitating the labor market adjustment of new arrivals. Although these two cohorts entered Australia only five years apart, their initial labor market outcomes varied dramatically. The results indicate that changes in immigration policy may have led to increased human capital endowments that in turn resulted in higher participation rates and reduced unemployment. At the same time, improvement in Australian labor market conditions and changes in income-support policy over the 1990s - which most likely altered the returns to human capital - were probably instrumental in reinforcing the effects of tighter immigrant selection criteria. As much as half of the fall in unemployment rates among women and one third the decline among men appears to have occurred as the result of changes in the returns to demographic and human capital characteristics.

JEL Classification: J6, J1

Keywords: immigrant, labor market assimilation, selection criteria, public policy

Corresponding author:

Deborah Cobb-Clark

SPEAR Centre, RSSS, Bld. 9

Australian National University

Canberra ACT, 0200

Australia

Tel.: +6126125 3267

Fax: +61261250182

Email:dcclark@coombs.anu.edu.au 


\section{Introduction}

International migration is an increasingly important economic phenomenon. The number of people worldwide living outside their country of birth now exceeds 120 million and more countries than ever are being classified as major suppliers or receivers of international migrants (Stalker, 2000). In the face of such massive movements of people, policy makers around the world are grappling with complicated issues surrounding the design and implementation of policies to facilitate the settlement of new arrivals.

Australia is an interesting case study for assessing the capacity of policy to promote immigrant settlement. First, Australia is a nation of immigrants. Nearly six million individuals have migrated to Australia since the post-war migration program began in October of 1945 . Of the 18.3 million individuals enumerated in the 1996 Australian Census, 23.0 percent were foreign born and an additional 18.6 percent were first generation Australians (DIMA, 1998). ${ }^{1}$ Second, a new data source - the Longitudinal Survey of Immigrants to Australia (LSIA) provides a unique opportunity to study two separate immigration cohorts as they enter Australia and begin looking for work. Unlike standard labor force surveys and censuses which provide only limited information about foreign-born individuals, the LSIA was specifically designed to enhance our understanding of the immigration and settlement process.

This paper explores the role of labor market conditions, income-support policy, and immigrant selection criteria in promoting labor market adjustment. Two separate cohorts of new entrants to Australia are compared. The first cohort entered as new immigrants in the early 1990s (1993-1995) while the second cohort entered in 1999-2000. Although these immigrants arrived in Australia only five years apart on average, their early labor market experiences were dramatically different. The employment-to-population ratio six months after migration was only 
31.5 percent for the first cohort, but 47.9 percent for the second. Labor force participation also increased between the two cohorts and the unemployment rate fell from 40.7 percent (Cohort 1) to 17.8 percent (Cohort 2).

A number of factors may account for these differences. In particular, there was substantial improvement in Australian labor market conditions over the latter half of the 1990s. Additionally, Australian immigration policy moved to place a greater emphasis on productivityrelated skills in the selection process, while income-support policy was changed to exclude most immigrants from social welfare payments for the first two years after arrival. Our interest lies in assessing these factors' potential role in promoting the labor market performance of new arrivals. The approach will be to use the detail of the LSIA data-in particular visa category, primary applicant status, gender, human capital characteristics, etc.- to pin point the source of the disparity in the labor market status and unemployment experience of the two entry cohorts. While not an identification strategy per se, this does allows us to begin to make progress in understanding the potential explanations for the improvement in labor market outcomes.

The results indicate that the 1999 changes to Australia's skilled immigration program may have played a large part in the improvement in labor market outcomes. The cohort of individuals entering Australia in 1999-2000 was more educated and had better English language skills than the previous cohort. These changes in human capital endowments resulted in increased participation rates and reduced unemployment. Furthermore, the effects of changing human capital endowments were not uniform, but were concentrated amongst those groups most likely to be subject to the tighter selection criteria. At the same time, it seems clear that changes in Australian labor market conditions and income-support policy over the 1990s — which most

\footnotetext{
${ }^{1}$ In comparison, during the same period 17.4 percent of the Canadian and 9.3 percent of the U.S. population was foreign born (OECD, 1995).
} 
likely altered the returns to human capital—were probably instrumental in reinforcing the effects of tighter immigrant selection criteria. Unemployment improved not only for skills-based immigrants (who were subject to the new points test), but also among family-based and to a lesser degree humanitarian immigrants who were not. As much as half of the fall in unemployment rates among women and one third the decline among men appears to have occurred as the result of changes in the returns to demographic and human capital characteristics.

The next section reviews details of changes in Australian labor market conditions, immigrant selection criteria, and income-support policy and outlines how each would be expected to influence the early labor market outcomes of new arrivals. Section 3 provides details of the LSIA data, while differences in the human capital endowments of the two LSIA cohorts are considered in Section 4. The determinants of labor market participation and unemployment are presented in Section 5. Subsequently, differences in labor market outcomes are decomposed into characteristics-related and returns-to-characteristics-related components. Finally, a discussion of the results and the conclusions of the analysis are presented in Section 7.

\section{Selection Criteria, Income-Support Policy, Labor Market Conditions in Australia}

For most immigrants, the success of the immigration decision often turns on a successful transition into the receiving-country labor market. This is particularly true in the first stages of immigrant settlement, but continues to be true even in later stages of family reunion and community formation (Wooden, et al., 1994). ${ }^{2}$ In the mid-1990s, the Australian government

\footnotetext{
2 See Wooden, et. al., (1994) and McDonald and Worswick, (1999), for reviews of studies comparing the labor market status of immigrants to native-born Australians at various stages of the business cycle. Cobb-Clark (2000) and Brown (1998) assess the relationship between the visa category and the labor market status of immigrants to Australia.
} 
adopted a number of policies designed to promote the successful labor market entry of new arrivals, and reduce the demand for taxpayer-funded income-support payments.

Changes over the 1990s:

Immigrants to Australia - like those to Canada or the United States - are selected on the basis of either labor market skills, family relationships, or out of humanitarian concerns. Australia's skilled immigration program - which is modeled closely on Canada's (Clarke, 1994) - relies on points tests as the primary mechanism for regulating the level and influencing the characteristics of skilled migrants. ${ }^{3}$ Changes to the immigration program in the late $1990 \mathrm{~s}$ gave an even greater emphasis to productivity-related characteristics in the immigrant selection process. First, the number of visas in the skill-based categories was increased from approximately 21,000 in $1993-94$ to 28,000 in $1998-99$, while the number of new arrivals holding family-based visas declined from approximately 25,500 to 21,500 (BIMPR, 1995; DIMA, 1999). ${ }^{4}$ Second, a limit was placed on the entry of parents, which had the effect of reducing the average age of family-based migrants (Richardson, et al., 2001). Third, the Department of Immigration and Multicultural Affairs (DIMA) established minimum age, skill, and English language criteria which skill-based immigrants must meet in addition to passing the

\footnotetext{
3 Australia's skilled immigration stream includes independent migrants without family relationships who are points tested (Independents), migrants with pre-arranged offers of employment (Employer Nomination Scheme (ENS)), and migrants intending to establish businesses in Australia who meet certain capital requirements (Business Skills (BS)). The Skilled Australia-Linked (SAL) program lies between the family-based and skill-based migration streams subjecting potential migrants to a points test which weights both skills and more distant family relationships. Due to small sample sizes, and the similarities in the two programs, it is customary to consider BS and ENS immigrants together.

4 Overall, 69,768 settlers arrived in Australia in 1993-1994 and by 1998-99 this number had grown to 84,143. The fall in Family Stream immigrants over this period was more than made up by a dramatic increase in the number of New Zealand citizens (who do not require visas) entering Australia under the 1973 Trans-Tasman Travel Arrangement. As a result, the proportion of the overall immigration flow admitted on the basis of skills expanded only modestly from 30.0 percent in 1993-94 to 33.2 percent in 1998-99 (BIMPR, 1995; DIMA, 1999). New Zealand citizens are outside the sampling frame of the LSIA, however, so the expansion in skill-based immigration is much greater in these data.
} 
points test. ${ }^{5}$ Changes to the points test itself resulted in additional points being awarded if the applicant's spouse also meets the minimum age, skill and English language requirements or if the applicant holds an Australian degree. Finally, DIMA now places greater emphasis on personal interviews in making decisions about the applications of skill-based immigrants.

These changes in selection criteria were coupled with changes in welfare policy tightening access to taxpayer-funded income-support programs. ${ }^{6}$ All immigrants arriving in Australia after January 1993 have been subject to a 26-week waiting period for access to unemployment benefits. However, many family-based immigrants in Cohort 1 would have been entitled to income-support payments on the basis of their Australian partner's eligibility and Special Benefit (a discretionary payment of last resort) was not subject to any waiting period. Since March of 1997, new arrivals - with the exception of humanitarian migrants - are prohibited from receiving practically all income-support payments (including Special Benefit) for the first two years after migration. ${ }^{7}$ Visa applicants are informed about the waiting period at several stages in the application process and three in four individuals captured in the second LSIA cohort report knowing about the ban before migration.

Improvements in overall conditions in the Australian labor market over the latter half of the 1990s most likely reinforced the effects of these policy changes in facilitating the labor market transition of new arrivals. Australian unemployment fell from 10.3 percent in September of 1993 to 7.1 percent in September of 1999. The number of individuals employed full-time rose 11.3 percent while part-time employment increased 24.2 percent. As a result, total employment

\footnotetext{
5 Specifically, all applicants must be under the age of 45, be proficient in English at the vocational level, and meet the Australian requirements for (and have recent experience in) an occupation set out on a skilled occupations list.

${ }^{6}$ This section is based on communication with the International Branch, Department of Family and Community Services.

7 Migrants in financial hardship whose circumstances have changed after arrival in Australia may still be able to access Special Benefit within the waiting period. In practice, however, this is very uncommon as an inability to find employment is not considered a change in circumstances.
} 
in the Australian labor market grew from just over 7.8 million to more than 8.9 million individuals over the six year period. ${ }^{8}$

\section{Effect of Policy Changes on Labor Market Outcomes:}

The Australian government's move in 1999 to select more highly-skilled immigrants would be expected to directly affect the average labor market outcomes of new arrivals: first, by altering the distribution of immigrants across visa categories and second, by increasing average skill levels. The latter occurring as the result of a change in the points test that gave more weight to age, English language ability, and recent experience in a skilled occupation. Note, that this primarily affected those actually subject to the points test-i.e., Independent and Skilled Australia-Linked (SAL) primary applicants ${ }^{9}$ - though the additional points awarded to applicants with spouses meeting the skill requirement would be expected to improve skills among Independent and SAL spouses as well. Furthermore, the points test is generally used to select male rather than female immigrants as women are disproportionately likely to enter as accompanying family members for whom no selection criteria apply. Only 5.4 percent of all female immigrants to Australia in 1990-1991 entered as primary applicants in one of the skillbased programs (Madden and Young, 1993). ${ }^{10}$ Generally speaking then, we expect selection policy to directly affect labor market outcomes by influencing observed human capital endowments.

In contrast, expanding employment and falling unemployment in the Australian labor market over the 1990s would be expected to have a direct influence on immigrant's labor market

\footnotetext{
${ }^{8}$ ABS Time Series Statistics, $\mathrm{dX}$ for Windows, Version 3.0.

${ }^{9}$ The primary applicant is the individual upon whom the approval to migrate was based. Once the primary applicant meets the selection criteria and is granted a visa, dependent family members (in practice, spouses and children) are automatically granted visas in the same category.
} 
outcomes by shifting the wage distribution and raising the returns to market work. Similarly, restricted access to income-support payments after 1997 would also be expected to affect the participation decisions and unemployment probabilities of immigrants by altering the costs and benefits of job search. Unlike changes in selection criteria that pertained mainly to individuals in specific immigration streams, differences in labor market conditions and income-support policy at the time of entry would be expected to affect foreign-born individuals more broadly by altering the returns to immigrants' human capital endowments.

Additionally, economic models of the migration decision itself demonstrate that relative economic conditions in sending and receiving countries generate selectivity in the characteristics of those individuals choosing to migrate (Borjas, 1987; Jasso and Rosenzweig, 1986; CobbClark, 1993; Greenwood, et. al., 1999). Changes in the state of the Australian labor market and in the generosity of Australian income-support policy would certainly have affected the returns to migration and perhaps altered the selectivity of the immigrant stream - though most likely not in the same direction. While improved labor market conditions would have raised the returns to migration for many potential immigrants, the change in welfare policy would be expected to result in many of those not confident of their ability to be economically independent increasingly choosing to stay at home. ${ }^{11}$ Variation in immigrants' observed characteristics are accounted for in the analysis. However, given the cross-sectional nature of the data, it is not possible to control for unobserved individual heterogeneity and as a result variation in the unobserved human capital characteristics of individuals in the two cohorts will be reflected in differences in the

\footnotetext{
${ }^{10}$ Women also tend to be over-represented in family classes and under-represented in skill classes in Canada and the United States (Houstoun, et. al., 1984; UN, 1995).

${ }^{11}$ In related work, Greenwood, et al., 1999 conclude that the specific social programs available in the source country are critical in shaping the decision to migrate to the United States.
} 
returns to related observed characteristics. There is in effect an omitted variables bias problemthe magnitude and direction of which may differ between cohorts.

Several indirect effects complicate the interpretation of the above dichotomy between human capital endowments (immigration policy) and returns (labor market conditions and income-support policy), however. First, although selection criteria are by their nature based on the observed characteristics of potential immigrants, the component of Australian policy that now places a greater emphasis on the interview process is an exception to this. This change would be expected to result in increased selection on certain forms of human capital which can be observed by immigration officials, but which are unobserved in our data. Such a policy effect would then be captured in returns to human capital rather than in human capital endowments themselves. Second, labor market conditions or income-support policy may - through an endogenous immigration process - affect observed (as well as unobserved) human capital characteristics. To the extent that both of these can be considered second-order effects, understanding the importance of human capital endowments and returns to human capital in altering immigrants' early labor market outcomes can provide useful information about the potential source of those changes.

\section{The Longitudinal Survey of Immigrants to Australia}

The LSIA was primarily designed to study the process of immigrant settlement. More than 300 questions about the settlement process—including labor market adjustment—are asked in each wave of the survey. LSIA data are particularly useful for understanding the role of selection criteria in facilitating immigrant settlement because of the availability of accurate 
information about detailed visa categories. ${ }^{12}$ In addition, primary applicants are distinguished from accompanying family members allowing the researcher to identify those individuals meeting the selection criteria. Both are critical to the analysis at hand.

The LSIA data-LSIA1 and LSIA2 - comprise two separate immigrant entry cohorts. ${ }^{13}$ LSIA1 generalizes to those primary applicants aged 15 and older arriving in Australia over a two-year period between September 1993 and August 1995. A total of 5192 primary applicants and 1837 migrating-unit spouses ${ }^{14}$ were captured in the first wave of LSIA1. A further 3124 primary applicants and 1094 migrating-unit spouses were sampled in wave 1 of LSIA2. These individuals represent the cohort of primary applicants over the age of 15 arriving between September 1999 to August 2000. New Zealand citizens, individuals under the age of 15, and people granted visas while in Australia are outside the scope of both LSIA1 and LSIA2.

Face-to-face interviews were conducted with both primary applicants and migrating-unit spouses. The form of the questionnaire is the same for primary applicants and spouses although primary applicants report additional information for other members of the household and for the household as a whole. With minor exceptions, the surveys are also the same across cohorts. Wave 1 interviews for both LSIA1 and LSIA2 were timed to occur approximately six months after arrival. Although panel information does exist for LSIA1, only cross-sectional data are available for LSIA2 and so to ensure that outcomes for the two cohorts are measured at the same point in the settlement process, the estimation sample is restricted to wave 1 data. $^{15}$

\footnotetext{
${ }^{12}$ Information about visa categories comes from DIMA administrative records and not self-reports.

${ }^{13}$ For more information about the technical details of the LSIA data see, the DIMA web page http://www.immi.gov.au/research/lsia, the technical documentation for the data, and Cobb-Clark (2001).

${ }^{14}$ For the purposes of the LSIA, the migrating unit includes all individuals migrating to Australia as part of the same visa application. The term "spouse" includes legal spouses, fiance(e)s, and de facto partners. In both LSIA cohorts more than 95 percent of those migrating-unit spouses present in the household were successfully interviewed.

${ }^{15}$ Specifically, the first LSIA cohort was re-interviewed approximately 18 months (wave 2) and 42 months (wave 3 ) after arrival and re-interviews of the second LSIA cohort are currently underway. There are no plans to re-
} 


\section{The Labor Market Outcomes and Human Capital Endowments of New Arrivals}

In addition to answering detailed questions about their migration experiences, LSIA respondents were also asked about their "current main activity". Individuations are coded as employed if they responded that their main activity was working as a wage or salary earner or conducting a business. Labor market participants are employed individuals or individuals responding that they were unemployed and looking for either part-time or full-time work. ${ }^{16}$ Further, all LSIA respondents - irrespective of current labor market status - were asked whether (and if so for how long) they had ever had ever been unemployed and looking for work since arriving in Australia. "Ever unemployed" is a dummy variable which equals one for individuals experiencing a period of unemployment since arrival and zero otherwise. "Months unemployed" captures - for current labor market participants only - the total duration of post-migration unemployment.

Participation rates, employment to population ratios, and unemployment indicators for both cohorts are reported separately by gender and visa category in Table 1 . These results document the dramatic improvement in immigrants' early labor market outcomes over the latter half of the 1990s. Large increases in the participation rates of immigrant women resulted in the overall labor force participation rate increasing from 53.1 percent (Cohort 1) to 58.3 percent (Cohort 2). This increase in participation was accompanied by rising employment and falling

interview Cohort 2 for a third time. Consequently, LSIA1 data span the first three and a half years after migration, while LSIA2 - when completed - will reflect only the first 18 months after arrival. As such the data provide information about the early settlement process rather than about long-run equilibrium behavior. The shortness of the two panels leaves many important questions regarding immigrant assimilation unanswered, but does allow us to make comparisons between the initial settlement behavior of two different immigration cohorts.

${ }^{16}$ Note that the LSIA measures of participation, employment, and unemployment differ from standard Australian Bureau of Statistics (ABS) definitions. As such, it is difficult to make comparisons between these results - in particular the unemployment rate - and those based on more standard definitions. This is not a particular problem for this analysis as it will be determinants of relative outcomes for different individuals that concern us. 
unemployment. Six months after migration almost one in two (47.9 percent) immigrants entering Australia between 1999 and 2000 had found employment. In contrast, the employmentto-population ratio was less than one in three for the cohort entering five years earlier. The unemployment rate of Cohort 2 immigrants was less than half that of Cohort 1 immigrants at the same stage of the settlement process. Finally, though more Cohort 2 immigrants reported experiencing some unemployment since arrival (29.5 percent versus 38.6 percent), the average length of time spent unemployed since arrival fell from 1.3 to 1.0 months. ${ }^{17}$

\section{Table 1 here}

Table 1 also documents the variation across visa categories in the participation rates and unemployment experiences of men and women in the two cohorts. For illustrative purposes, participation rates, unemployment rates, and months unemployed are shown in Figures $1-3$. In general, the results indicate that immigrants entering Australia in 1999 - 2000 had better labor market outcomes shortly after arrival irrespective of the type of visa they held. With the exception of BS/ENS immigrants who experienced constant unemployment, unemployment rates improved across the board (see Figure 2). The fall in unemployment (from 27.9 to 9.5 percent for men and from 31.3 to 11.2 percent for women) was particularly impressive for Independent migrants who were subject to the new points test, but was also evident for Family Stream and Humanitarian immigrants who were not. The only exception to the trend in improving labor market outcomes was a fall in the participation rate (see Figure 1) of BS/ENS men and men and women holding Humanitarian visas.

\section{Figures $1-3$ here}

\footnotetext{
${ }^{17}$ This occurred even though Cohort 2 immigrants had been in Australia somewhat longer on average at the interview date than Cohort 1 immigrants.
} 
Table 2 compares the productivity-related characteristics of the two LSIA cohorts. The distribution of LSIA immigrants across visa categories highlights the expansion of the skilled immigration program and the relative scaling back of the family and humanitarian streams. The proportion of individuals entering on a skills-based visa increased from one in three (35.0 percent) in LSIA1 to one in two (49.7 percent) in LSIA2. Family Stream immigrants made up 48.5 percent of the first LSIA cohort, but only 41.4 percent of the second, while the proportion of Humanitarian immigrants fell by almost half over the five years separating the two entry cohorts.

\section{Table 2 here}

As expected, there are large gender differences in the proportion of LSIA immigrants subject to Australia's points test. Primary applicants in the SAL and Independent immigration programs account for approximately one third of all men in our two LSIA cohorts. In contrast, only 9.5 percent of Cohort 1 women and 16.8 percent of Cohort 2 women entered Australia as the primary applicant in one of the two skill-based programs subject to points testing.

How much of the variation in the average outcomes of the two cohorts results from differences in the distribution of immigrants across visa categories? If men in LSIA1 had retained their own visa-specific outcomes, but had been distributed across the visa categories in the same manner as LSIA2 men, their participation rate would have increased from 74.0 to 77.4 percent while their unemployment rate would have fallen from 39.0 to 32.1 percent. In comparison, LSIA2 men had a participation rate of 76.5 percent and an unemployment rate of 18.5 percent (see Table 1). Applying the LSIA2 visa distribution to the outcomes of women in LSIA1 results in a predicted participation rate of 38.7 percent and a predicted unemployment rate of 42.6 percent. In comparison, LSIA2 women had actual participation and unemployment rates of 42.6 and 16.7 percent respectively. Thus, while all of the increase in labor market 
participation of immigrant men - and almost half that of immigrant women - can be accounted for by changes in the distribution of individuals across visa categories, this is not true of the unemployment rate. Even after standardizing the distribution across visa categories, the unemployment rate of men and women entering in the early 1990s would have remained twice as high as that of those entering in the late 1990s.

Though the demographic make up — average age, gender ratio, and marital status — of the two cohorts is much the same (see Table 2), there are striking differences in human capital endowments. Consistent with changes in selection criteria, the cohort of individuals entering Australia in 1999-2000 is more educated and has better English language skills ${ }^{18}$ than the previous cohort. They also were more likely to have been working in a professional occupation and less likely to have been not employed in the former home country in the year prior to immigration. ${ }^{19}$ Overall, almost half (45.6 percent) of Cohort 2 had recent labor market experience in a professional occupation at the time of migration. This was true of just over one third (35.0 percent) of individuals in the first cohort. Finally, there are differences in the source countries of the two cohorts. Cohort 2 immigrants are more likely (55.2 percent versus 48.5 percent) to come from a country where English is widely spoken and with cultural traditions and institutions that closely resemble Australia's. ${ }^{20}$ These changes in human capital characteristics facilitate employment and make the settlement process easier.

\footnotetext{
${ }^{18}$ LSIA respondents were asked to report about their ability to speak English. Those who reported speaking English "only" or "best" are classified as "native" English speakers. Non-native speakers who reported speaking English "very well" or "well" are combined to form the "English well" category. Non-native speakers who reported speaking English "badly" or "not at all" form the "English badly" category.

${ }^{19}$ Although LSIA data do not contain direct measures of labor market experience, LSIA respondents were asked about their labor market experiences in their former home country in the year prior to migration. Individuals employed at some point in the year prior to migration reported their occupation. These occupations have been coded into three major categories: professional, skilled, unskilled. Individuals not employed in the 12 months before migration are coded as "not employed". Finally, "time unemployed" measures the number of months in the year prior to migration that an individual reported being unemployed and looking for work.

${ }^{20}$ In this analysis source countries are divided into English proficiency groups based on the English-speaking ability of recent immigrants to Australia (see DIMA, 1996). Group 1 includes the mainly English speaking countries
} 


\section{The Determinants of Labor Market Participation and Unemployment}

There are several methods for estimating the determinants of participation, employment, and unemployment. ${ }^{21}$ In the end, the choice of the estimation strategy often depends on how one wishes to interpret the results. This paper separately estimates the determinants of participation and the determinants of unemployment conditional upon participation because this method provides the more useful interpretation. This approach is completely analogous to estimating the factors related to participation and unemployment rates and it is these outcome measures that are of particular interest to policy makers setting selection criteria. ${ }^{22}$ Given this, three separate labor market outcomes are considered: 1) labor market participation—and for participants—2) current unemployment status and 3) months spent unemployed and looking for work since migration. This allows us to shed light on both an immigrant's desire to work and on those factors related to successfully finding employment.

\section{Empirical Framework:}

Immigrants are assumed to participate in the Australian labor market whenever the returns to market work exceed the value of their time in alternative activities. Specifically, the probability of immigrant $i$ participating in the Australian labor market at the interview date (approximately six months after migration) is assumed to be given by:

$$
\operatorname{Pr}\left(P_{i j}=1\right)=\operatorname{Pr}\left(X_{i j} \beta_{j}+\varepsilon_{j}>0\right)=\Phi\left(X_{i j} \beta_{j}\right)
$$

(Canada, New Zealand, United Kingdom, Ireland, United States, and South Africa). Immigrants from these countries rate 98 percent or higher on the English proficiency index. Group 2 includes those countries with a rating of 80 percent or higher, while Group 3 includes countries with a rating between 50 percent and 80 percent. Countries with a rating of less than 50 percent make up Group 4.

${ }^{21}$ See Cobb-Clark (2000) for a review.

${ }^{22}$ This approach is also more in keeping with the spirit of the nested discrete choice models. 
where $j=1,2$ indexes cohorts, $P_{i j}=1$ for labor market participants and 0 otherwise, $\varepsilon_{j} \sim N(0,1)$, and $\Phi$ is the standard normal cumulative distribution function, and $\beta_{j}$ is a vector of parameters to be estimated.

Conditional upon seeking market work, we consider two alternative measures of an immigrant's unemployment experience in the first six months in Australia. First, the probability of immigrant $i$ being unemployed at the interview date is assumed to be given by:

$$
\operatorname{Pr}\left(U_{i j}=1 \mid P_{i j}=1\right)=\operatorname{Pr}\left(X_{i j} \phi_{j}+\omega_{j}>0 \mid P_{i j}=1\right)=\Phi\left(X_{i j} \phi_{j}\right)
$$

where $U_{i j}=1$ for those unemployed (and 0 otherwise), $\omega_{j} \sim N(0,1)$ and $\phi_{j}$ is a vector of returns. Second, the number of months $\left(M_{i j}\right)$ an immigrant spent unemployed and looking for work between the arrival and interview dates is given by:

$$
M_{i j}=X_{i j} \delta_{j}+\eta_{i j}
$$

where $\delta_{j}$ is a vector of coefficients to be estimated and $\eta_{i j} \sim N\left(\mu_{j}, \sigma_{j}^{2}\right)$. In equations (1) - (3), $X_{i j}$ is a vector of human capital (education, English ability, English language background), demographic (age, marital status, children) and geographic (unemployment rates $^{23}$ and state of residence) variables thought to be related to the value of time in non-market activities and to labor market productivity. Although the data do not provide a direct measure of labor market experience, pre-migration occupation and employment status are included to act as controls for the effects of labor market experience immediately prior to migration. The model also includes controls for visa category, primary applicant status, and the number of weeks since migration.

\footnotetext{
${ }^{23}$ Specifically, Australian Bureau of Statistics (ABS) sources were used to obtain monthly unemployment rates separately for men and women in each State or Territory. Using the month and year of interview these aggregate unemployment rates were merged to individual LSIA records. Note that LSIA measures of unemployment differ from standard ABS definitions.
} 
Equation (1) was estimated for male and female immigrants aged 22 - 60 using a probit model. ${ }^{24}$ Using the working-aged sample of labor market participants, Equation (2) was also estimated using a probit model while equation (3) was estimated using OLS. In each case, model 1 restricts the coefficients to be the same in each cohort allowing for only a simple intercept shift, while model 2 estimates separate slope coefficients for each cohort. The results (probit marginal effects ${ }^{25}$, OLS coefficients, and standard errors) from each regression are reported in Tables $3-5$. In addition, Tables $3-5$ report the results of $\mathrm{Chi}^{2}$ tests that test whether the differences in LSIA2 and LSIA1 coefficients are significant. ${ }^{26}$ Unfortunately, small sample sizes (particularly for Cohort 2) preclude estimating the models separately by visa category. ${ }^{27}$

\section{Tables 3,4 and 5 here}

\section{The Immigration Process:}

Women entering Australia in 1999-2000 have a labor force participation rate that is 7.0 percentage points higher and an unemployment rate that is 10.8 percentage points lower than otherwise similar women migrating to Australia in the early 1990s. (See Table 3.) Cohort 2 women also spent approximately two fewer weeks unemployed in the first six months after migration, although this difference was not significant. In contrast, there is no significant difference in the participation or unemployment experiences of male immigrants in the two LSIA

24 All estimation was done in STATA 7.0.

${ }^{25}$ Note that for continuous variables such as age, the probit marginal effect represents the effect of an infinitesimal change in the independent variable on the probability that an immigrant was in a specific labor market state. For discrete variables, such as marital status, the marginal effect represents the effect of a one-unit change in the independent variable. See the STATA manual for more details. Actual probit coefficients and robust standard errors are available upon request.

${ }^{26}$ These tests were conducted by estimating a fully interacted version of each of the equations. Coefficients on the interactions then reflect the difference in the determinants of the two cohorts. The results reported in Tables $3-5$ are the $\mathrm{p}$ values from the $\mathrm{Chi}^{2}$ tests of the significance of the interaction terms. Individual tests were performed for PA status and time since migration. Joint tests were performed for other subsets of variables. The significance level for joint test of all interactions in the model is reported in the final row of each Table.

${ }^{27}$ In particular, there are only 19 LSIA2 women holding Humanitarian visas participated in the labor market six months after migration making estimation of labor market outcomes impossible for this group. For other groups, small samples and limited variation prevented estimation of a model that included the complete range of controls. 
cohorts once differences in productivity-related characteristics are taken into account. (See Table 4.) Consistent with changes in selection criteria, it appears that for men the large decline in the unconditional unemployment rates of new arrivals (see Table 1) between the two cohorts may be the result of differences in human capital endowments. For women, the gap in participation rates between the two cohorts is much the same once characteristics are controlled, while a smaller - though still sizeable — gap in conditional unemployment rates remains. This suggests changes in the returns to characteristics led to increased participation and reduced unemployment for foreign-born women.

Interestingly, the gap in the participation rates of primary applicants (who are subject to selection criteria) and spouses (who are not) fell somewhat for men (7.4 to 4.2 percentage points). Similarly, women entering Australia as primary applicants between 1993-1995 had an unemployment rate that was 19.2 percentage points lower and an average period of unemployment that was one third of a month longer than women entering as spouses over the same period. However, the participation rates and unemployment experiences of female primary applicants were not significantly different from those of female spouses in Cohort 2. This narrowing of the gap between individuals entering as primary applicants and those entering as spouses - though not statistically significant at conventional levels - is consistent with the 1999 changes in the points test which awarded extra points to those primary applicants whose spouses also met the minimum age, language, and skill requirements.

Diversity in labor market experiences across visa categories is also informative about the role of selection criteria in promoting labor market entry and in facilitating market employment. With the exception of the number of months LSIA women spend unemployed, changes over the 1990 s in the relationship between visa category and labor market outcomes are statistically 
significant - particularly for men. In particular, participation rates of immigrants in the Independent and Skilled Australia-Linked (SAL) streams-which are points tested-increased over time relative to those of immigrants in the Business Skills/Employer Nomination Scheme (BS/ENS) programs. Men and women holding SAL visas who entered Australia during the early 1990s had a participation rate that was 3.4 and 6.5 percentage points higher respectively than similar men and women holding BS/ENS visas. Amongst Cohort 2 men and women these participation gaps had increased to 12.5 and 19.6 percentage points respectively. At the same time, there was also convergence in relative unemployment experiences. For example, Independent men had a probability of being unemployed that was 56.8 percentage points higher than BS/ENS migrants in Cohort 1, but only 13.0 percentage points higher in Cohort 2. Similarly, women holding Independent and SAL visas had unemployment rates in Cohort 1 that were more than forty percentage points higher than that of women with BS/ENS visas. Amongst Cohort 2 women, this difference was 21.9 percentage points for SAL immigrants and only 6.1 percentage points for Independents. Convergence in the length of time spent unemployed and looking for work was also evident for Cohort 2. These results are consistent with changes in the points test which increased the weight given to skills in the selection process for Independent and SAL programs, but left the selection process in the ENS/BS program largely unaffected.

At the same time, these patterns are even more striking for men and women in the Family Stream who also are not subject to a points test. They too dramatically improved their labor market position six months after arrival relative to immigrants in the BS/ENS stream. ${ }^{28}$ In fact, only refugees failed to see a substantial reduction in their relative unemployment. Despite convergence in outcomes for other Cohort 2 immigrants, Humanitarian immigrants continued to 
have unemployment rates that were 76.4 and 57.8 percentage points higher than BS/ENS immigrants. Perhaps the most striking change, however, is the deterioration in the relative probability that Humanitarian immigrants, particularly women, are participating in the Australian labor market. This decline (see also Figure 1) occurs although there was little change in the selection process for refugees over the period and despite improvement in labor market conditions and a tightening of access to income-support payments that would have been expected to lead to higher participation in the labor market. ${ }^{29}$

Thus, differences in relative labor market outcomes between primary applicants and spouses across visa categories are consistent with the 1999 changes in Australian immigration policy that gave greater weight to skills in the selection process. At the same time, the patterns for Family Stream and Humanitarian immigrants who were not subject to substantial changes in selection criteria suggest that changes in labor market conditions and income-support policy also may play an important role in producing these results.

\section{Human Capital Characteristics:}

Insight into the relative importance of the general improvement in Australian labor market conditions may be gained by explicitly considering how the returns to labor market skills changed between the two LSIA cohorts. Over the 1990s in Australia there was convergence in the labor market participation rates of new arrivals with diverse English language abilities. The participation gap between male native English speakers and otherwise similar men who speak English badly fell from 26.9 percentage points (Cohort 1) to 14.8 percentage points (Cohort 2).

\footnotetext{
${ }^{28}$ Although, limitations were placed on the entry of parents reducing the average age of Family Stream immigrants (Richardson, et al., 2001), it is unlikely that this alone would be sufficient to generate this widespread improvement in the labor market position of working-aged adults once age is controlled in the regression.
} 
(See Table 3.) There is also evidence that the employment penalty faced by non-native English speakers in Cohort 1 disappears when we consider Cohort 2 immigrants. Women who entered Australia in the early 1990s and who spoke English badly, for example, had a probability of being unemployed six months after arrival that was 34.2 percentage points higher than women who reported that they were native English speakers. (See Table 4.) There was no significant difference in the unemployment rates of Cohort 2 women who did and did not speak English, however. This represents a significant change in the relationship between English ability and the unemployment rates of women. A similar trend is observed for men, though it is not significant.

Changes in the pattern of relative participation rates across education categories are more difficult to quantify, however it appears that for both men and women there was a deterioration in the participation rates of those attending (but not completing) high school relative to those holding a technical or trade degree. Furthermore, the gap in the participation rates of foreignborn men enrolled and not enrolled in education was larger for Cohort 1 than Cohort 2, though there was little change in the relative participation rates of foreign-born women. Neither premigration education level nor post-migration enrollment in education are strongly related to the unemployment experiences of labor market participants once other factors are taken into account, however. The exception is that Cohort 1 men with some university education have a higher probability of (and spend longer) being unemployed than similar men with technical or trade degrees. Overall, a significant change over the 1990s occurred in the relationship between male immigrants' education and their participation and unemployment rates. Results are similar for women, although the effects are not as large. Unlike men, women with less than ten years of education have better employment outcomes than do women with technical or trade degrees.

\footnotetext{
${ }^{29}$ This decline in participation is unfortunate since previous evidence suggests that the employment of wives in refugee families generates a substantial proportion of family income and is thus very important to the economic
} 
Finally, labor market experiences in the twelve months prior to immigration are important in explaining labor market outcomes shortly after arrival in Australia. Labor market attachment in the year before migration is related to the probability that a foreign-born woman is participating in the labor market six months after migration (particularly for Cohort 2 women), but is unrelated to post-migration unemployment conditional on participation. ${ }^{30}$ Recent unemployment is related to higher unemployment in Australia, though only for those women entering Australia between 1999 - 2000. There were significant changes in the relationship between men's labor market outcomes prior to migration and post-migration unemployment rates. Irrespective of previous occupation, Cohort 2 men who were employed in the 12 months prior to migration have a lower probability of being unemployed six months after arrival in Australia. In contrast, Cohort 1 men who worked in an unskilled occupation prior to migration had a significantly higher (19.7 percentage points) probability of being unemployed after arrival in Australia.

Thus, it seems to be the case that changes in labor market conditions and income-support policy between the early and late 1990s served to alter the relative returns to English language ability, education, and pre-migration labor market experience. While the employment penalty for being a non-native English speaker fell between Cohort 1 and Cohort 2 for both men and women, the relative returns to pre-migration labor market experience were higher for men in Cohort 2 than in Cohort 1. Alternatively, there may be variation over time in the ability level of individuals within skill categories that are not captured by the model and which lead to changes in relative returns.

well-being of the family (Cobb-Clark and Connolly, 2001).

${ }^{30}$ These changes are statistically significant at the ten percent level. 


\section{Decomposition Analysis}

In this section, our focus is on decomposing relative improvements in the participation rate and unemployment experience of new arrivals in Australia into characteristics-related and returns-to-characteristics-related components. Generally speaking, we expect that the influence of changes in immigration policy will have its most direct effect on changes in characteristics themselves, while labor market conditions and income-support policy work most directly alter the Australian labor market returns to characteristics. Indirect, second-order effects (see Section 2) serve to confound these interpretations, however. Still, the following decomposition analysis advances sheds light on the potential role of immigrant selection criteria, labor market conditions, and income-support policy in facilitating immigrants' early labor market outcomes.

\section{Decomposition Methodology:}

Let us first consider labor market participation. (The decomposition procedure for the probability of being unemployed is analogous.) Recall that $X_{i j}$ is a vector of demographic and human capital characteristics influencing labor market status, while $\beta_{j}$ is a vector of returns to those characteristics. Let $\hat{X}_{j}$ capture the characteristics of a representative person of cohort $j .{ }^{31}$ The predicted cohort gap in the probability of participating in the Australian labor market is given by:

\footnotetext{
31 The curvature of the normal distribution implies that using the sample means $\bar{X}_{j}$ to characterize the representative person results in predicted probabilities of participation that do not equal the sample averages. Furthermore, the problem differs by LSIA cohort, leading the participation gap between Cohort 1 and Cohort 2, for example, to be overstated for men and understated for women. Following, Doiron and Riddell (1994), I define a representative foreign-born individual $\left(\hat{X}_{j}\right)$ such that he (she) has a predicted probability of, in this case, labor market participation equal to the cohort sample average and such that his (her) endowments are in the same proportion as the average endowments of foreign-born men (women) in the cohort. In effect, $\hat{X}_{j}=a_{j} \bar{X}_{j}$ where $a_{j}$ is a cohort-specific scaling factor.
} 


$$
\hat{p}_{2}-\hat{p}_{1}=\Phi\left(\hat{X}_{2} \hat{\beta}_{2}\right)-\Phi\left(\hat{X}_{1} \hat{\beta}_{1}\right)
$$

Due to the non-linearity of the cumulative normal distribution, the cohort gap in the probability of participation is a non-linear function of $\hat{X}_{j}$ and $\hat{\beta}_{j}$ making standard decompositions impossible. To avoid this Doiron and Riddell (1994) suggest using a linear approximation. Specifically,

$$
\hat{p}_{2}-\hat{p}_{1}=\Phi\left(\hat{X}_{2} \hat{\beta}_{2}\right)-\Phi\left(\hat{X}_{1} \hat{\beta}_{1}\right) \cong \frac{\partial \Phi(\psi)}{\partial \psi}\left(\hat{X}_{2} \hat{\beta}_{2}-\hat{X}_{1} \hat{\beta}_{1}\right)
$$

where $\psi=\left(N_{2} \hat{X}_{2} \hat{\beta}_{2}+N_{1} \hat{X}_{1} \hat{\beta}_{1}\right) /\left(N_{2}+N_{1}\right)$ is simply the predicted probability of participation for the representative members of Cohort 1 and Cohort 2 weighted by the respective sample sizes $N_{1}$ and $N_{2} \cdot{ }^{32}$ By adding and subtracting $\frac{\partial \Phi(\psi)}{\partial \psi} \hat{X}_{2} \hat{\beta}_{1}$ from the right hand side of equation (5) we can decompose the participation gap into returns- and characteristics-related components in the following manner:

$$
\hat{p}_{2}-\hat{p}_{1} \cong \frac{\partial \Phi(\psi)}{\partial \psi}\left[\hat{X}_{2}\left(\hat{\beta}_{2}-\hat{\beta}_{1}\right)+\hat{\beta}_{1}\left(\hat{X}_{2}-\hat{X}_{1}\right)\right]
$$

The decomposition given by equation (6) is obviously not unique. To assess the robustness of the results, two decompositions of the promotion gap are considered: the one given by equation (6) - $\mathrm{D}^{1}$ (which weights differences in characteristics by Cohort 1 returns)-and $\mathrm{D}^{2}$ (which weights differences in characteristics by Cohort 2 returns) and results from adding and subtracting $\frac{\partial \Phi(\psi)}{\partial \psi}\left(\hat{X}_{1} \hat{\beta}_{2}\right)$ in (5).

\footnotetext{
${ }^{32}$ The first term on the right hand side is the standard normal probability density function evaluated at $\psi$.
} 
The above procedure was also used to decompose the probability of being unemployed at the time of interview into characteristics- and returns-related components. The decomposition of the length of time spent unemployed and looking for work is given by:

$$
\begin{aligned}
& D^{1}=\Delta M=\bar{X}_{2}\left(\hat{\beta}_{2}-\hat{\beta}_{1}\right)+\hat{\beta}_{1}\left(\bar{X}_{2}-\bar{X}_{1}\right) \\
& D^{2}=\Delta M=\bar{X}_{1}\left(\hat{\beta}_{2}-\hat{\beta}_{1}\right)+\hat{\beta}_{2}\left(\bar{X}_{2}-\bar{X}_{1}\right)
\end{aligned}
$$

Results:

The results of the decomposition analysis for newly-arrived men and women are presented in Table 5. Consider first the sources of cohort differences in labor market participation rates. Women entering Australia between 1999 - 2000 (Cohort 2) had a labor market participation rate six months after arrival that was 5.2 percentage points higher than women who entered approximately five years earlier (Cohort 1). Most if not all-i.e., between 75.4 and 111.8 percent - of this increase is due to differences in the demographic and productivity-related characteristics of the women in the two entry cohorts. In contrast, differences in the participation rates of foreign-born men in the two LSIA cohorts are much smaller (0.6 percentage points) and not statistically significant. This difference appears to be mainly due to differences in returns to characteristics rather than differences in the characteristics themselves, though given the magnitude of the gap, this decomposition is somewhat sensitive to model specification.

\section{Table 5 Here}

Perhaps the most important change in the labor market status of individuals in the two LSIA cohorts is in the dramatic decline in the probability that an individual participating in the Australian labor market had not found employment by the date of the first interview (approximately six months after arrival). Women in Cohort 2 had an unemployment rate that was 25.7 percentage points lower than women in Cohort 1, while the probability of 
unemployment for foreign-born men fell by 19.7 percentage points between the two cohorts. Approximately half (15.0 to 11.7$)$ of the fall in unemployment among women appears due to changes in average human capital endowments of the two entry cohorts, with the remainder (12.6 to 15.9 percentage points) occurring as the result of changes in the returns to those characteristics. At the same time, differences in human capital endowments play a larger role in explaining the fall in male unemployment rates. Changes in characteristics explain almost twothirds of the decline in the probability of unemployment when we weight relative characteristics by Cohort 1 returns $\left(D^{1}\right)$ and more than explain the decline when relative characteristics are weighted by Cohort 2 returns $\left(\mathrm{D}^{2}\right)$. This is not surprising given that men are disproportionately subject to the points test (see Table 2).

Conditional on labor market participation, the average length of time new arrivals spent unemployed and looking for work in the first six months in Australia fell by approximately three weeks. Differences in demographic characteristics and human capital endowments between the two entry cohorts are important in explaining the shorter periods of unemployment for both men and women. Differences in characteristics explain between half and almost all of this change depending on the decomposition method used.

\section{Discussion and Conclusions}

Although the two LSIA cohorts entered Australia only five years apart on average, their early labor market experiences were dramatically different. Driven by the behavior of women, aggregate labor market participation rates increased from 53.1 percent (Cohort 1) to 58.3 percent (Cohort 2) and there was a spectacular fall in the unemployment rate (40.7 to 17.8 percent). 
The 1999 changes to Australia's skilled immigration program seem to have played a large part in producing these changes. Consistent with changes in selection criteria, the cohort of individuals entering Australia in 1999-2000 was more educated and had better English language skills than the previous cohort. They also were more likely to have been working in a professional occupation and less likely to have been not employed in the former home country in the year prior to immigration. These changes in human capital endowments were instrumental in generating the increase in participation rates. More than half of the cohort participation gap is eliminated by standardizing the visa distribution, while the decomposition analysis suggests that at least three-quarters (and perhaps all) of the increase in the labor market participation of foreign-born women can be attributed to changes in characteristics.

Furthermore, the effects of changing human capital endowments are not uniform, but are concentrated amongst those groups most likely to be subject to the tighter selection criteria. There is evidence that the gap between individuals entering as primary applicants and those entering as spouses narrowed which is consistent with the 1999 changes in the points test which awarded extra points to those primary applicants whose spouses also met the minimum age, language, and skill requirements. Men are much more likely than women to be subject to Australia's points test and there is evidence that for them changes in human capital endowments are more important in explaining the improvement in labor market outcomes. For example, there is no significant difference in the participation behavior or unemployment experiences of male immigrants in the two LSIA cohorts once differences in productivity-related characteristics are taken into account. For women, on the other hand, the cohort gap in participation rates is much the same once characteristics are controlled, while a smaller - though still sizeable — gap in 
conditional unemployment rates remains. These gender differences are also reflected to a large degree in the decomposition analysis.

At the same time, it seems clear that changes in Australian labor market conditions and income-support policy over the $1990 \mathrm{~s}$ — which altered the returns to human capital—reinforced the effects of tighter immigrant selection criteria. With the exception of Business Skills (BS) and Employer Nomination Scheme (ENS) immigrants (who experienced constant unemployment rates), relative unemployment improved across the board. The fall in unemployment was particularly impressive for Independent migrants (from 29.1 to 10.1 percent) who were subject to the new points test, but was also evident for Family Stream and to a lesser degree Humanitarian immigrants who were not. As much as half of the fall in unemployment rates among women and one third the decline among men appears to have occurred as the result of changes in the returns to demographic and human capital characteristics.

These results are necessarily open to alternative interpretations, however. The decomposition analysis is informative about the extent to which improving labor market outcomes were driven by changes in human capital endowments as opposed to altered returns to human capital. Still, we cannot completely rule out the possibility that changes in immigrants observed human capital endowments occurred primarily as a result of changes in labor market conditions or income-support policy rather than immigrant selection criteria. Nor can we completely dismiss the possibility that altered returns to immigrants skills are primarily due to changes in immigration policy rather than improved labor market conditions or changes to the income-support system.

Furthermore, the cross-sectional nature of the data results in an inability to account for unobserved individual heterogeneity in this analysis. This is potentially quite important as 
changes in the state of the Australian labor market and the generosity of Australian incomesupport policy would have directly affected the returns to migration, altering the selectivity of the immigrant stream. Given this, divergence in the estimated returns to characteristics for the two cohorts may be driven to a degree by differences in unobserved heterogeneity—generated by the migration process - that is not accounted for in the estimation process. Whether changes in labor market conditions and income-support policy affected outcomes by altering the migration decision of potential migrants or by altering the opportunities of immigrants already resident in Australia remains an interesting question for future research.

Finally, it is important to note that the outcomes analyzed in this paper are measured very early in the settlement process (six months after arrival) and do not reflect long-run equilibrium differences between the two immigration cohorts considered. It is not clear whether immigrants entering Australia between 1999 and 2000 will have a persistent labor market advantage over earlier arrivals or merely a head start. In fact, a growing literature based on LSIA data has documented the rapid improvement in labor market outcomes for members of the first LSIA cohort. $^{33}$ Eventually, once the LSIA data collection is completed, it will be possible to compare outcomes for these two cohorts 18 months after arrival. Unfortunately, analysis of longer-term outcomes awaits the development of additional data sources.

\footnotetext{
${ }^{33}$ In particular, three and a half years after arrival, the employment to population ratio for LSIA1 had increased to 56 percent (about 15 percentage points less than the Australian average), while the unemployment rates of Independent and SAL immigrants were indistinguishable from that of the Australian population. Unemployment rates for Family Preference (18 percent) and Humanitarian ( 31 percent) immigrants - though much lower than upon arrival remained much higher than average (Richardson, et al., 2001).
} 


\section{References:}

Borjas, George J., 1987. "Self-Selection and the Earnings of Immigrants." American Economic Review, 77(4), pp. $531-553$.

Brown, Richard P.C., 1998. "Comparative Labor Market Performance of Visaed and Non-Visaed Migrants: Pacific Islanders in Sydney", Journal of Population Economics, Vol. 11, pp. $395-411$.

Bureau of Immigration, Multicultural, and Population Research (BIMPR), 1995. Settler Arrivals: 1993 - 1994, April 1995, Canberra: Australian Government Publishing Service.

Clarke, Harry. (1994) The Rationale for Forward Planning and Stability in the Migration Program, Bureau of Immigration, Multicultural and Population and Research, Canberra: Australian Government Publishing Service.

Cobb-Clark, Deborah A., 1993. "Immigrant Selectivity and Wages: The Evidence for Women", American Economic Review, 83(4), September, pp. 986-993.

-----, 2000 "Do Selection Criteria Make a Difference? Visa Category and the Labor Market Status of Immigrants to Australia. The Economic Record, 76(232), March.

-----, 2001. "The Longitudinal Survey of Immigrants to Australia", Australian Economic Review, forthcoming.

----- and Marie D. Connolly, 2001. "Wives and Mothers: The Labor-Market Experiences of Immigrant Women" in Earnings Inequality in Australia, Jeff Borland, Robert Gregory, and Peter Sheehan (ed). Melbourne: Centre for Strategic Studies, Victoria University, pp. 78-94.

Department of Immigration and Multicultural Affairs (DIMA), 1998, Population Flows: Immigration Aspects, Canberra: Australian Government Publishing Service.

-----, 1999, Settler Arrivals: 1998 - 1999, December 1999, Canberra: Australian Government Publishing Service.

-----, 1996 Classification of Countries into English Proficiency Groups (C96.1A Revised), April, Canberra: Australian Government Publishing Service.

Doiron, Denise J. and W. Craig Riddell, 1994. "The Impact of Unionization on Male-Female Earnings Differences in Canada", Journal of Human Resources, Vol. XXIX(2), Spring, pp. 504-534.

Greenwood, Michael J., John D. McDowell, Donald M. Waldman, and Steven S. Zahniser, 1999. "The Influence of Social Programs in Sources Countries on Various Classes of U.S. 
Immigration", Journal of the American Statistical Association, March, Vol. 94 (445), pp. $64-74$.

Houstoun, Marion F., Roger G. Kramer, and Joan Mackin Barrett, 1984. "Female Predominance in Immigration in the United States Since 1930: A First Look", International Migration Review, Vol. 38 (4), pp. $908-963$.

Jasso, Guillermina and Mark R. Rosenzweig, 1986. "What's in a Name? Country of Origin Influences on the Earnings of Immigrants in the United States" in Human Capital and Development, 4, JAI Press.

McDonald, James Ted and Christopher Worswick, 1999. "The Earnings of Immigrant Men in Australia: Assimilation, Cohort Effects, and Macroeconomic Conditions" Economic Record, 75(228), March, pp. $49-62$.

Madden, Ros and Susan Young, 1993. Women and Men Immigrating to Australia: Their Characteristics and Immigration Decisions, Bureau of Immigration Research, Canberra : Australian Government Publishing Service.

Organization for Economic Co-operation and Development, (1995). Trends in International Migration, OECD, Paris.

Richardson, Sue, Frances Robertson, and Diana Illsley, 2001. The Labor Force Experiences of New Migrants. August, 2001. Canberra: Australian Government Publishing Service.

Stalker, Peter (2000). Workers Without Frontiers: The Impact of Globalization on International Migration, Boulder, CO: Lynne Rienner Publishers, Inc.

United Nations (UN), Department for Economic and Social Information and Policy Analysis, Population Division, 1995. International Migration Policies and the Status of Female Migrant, New York: United Nations.

Wooden, Mark. Migrant Labor Market Status. Bureau of Immigration and Population Research. Canberra: Australian Government Printing Service. 
Table 1: Labor Market Outcomes

First and Second LSIA Cohorts by Gender and Visa Category (Means ${ }^{\mathrm{a}}$ and Standard Deviations)

\begin{tabular}{|c|c|c|c|c|c|}
\hline & $\begin{array}{c}\text { Participation } \\
\text { Rate }\end{array}$ & $\begin{array}{c}\text { Employment } \\
\text { to Population } \\
\text { Ratio }\end{array}$ & $\begin{array}{c}\text { Unemployment } \\
\text { Rate }\end{array}$ & $\begin{array}{c}\text { Months } \\
\text { Unemployed }\end{array}$ & $\begin{array}{c}\text { Proportion } \\
\text { Ever } \\
\text { Unemployed }\end{array}$ \\
\hline & Mean (Std.) & Mean (Std.) & Mean (Std.) & Mean (Std.) & Mean (Std.) \\
\hline \multicolumn{6}{|l|}{ Total } \\
\hline Cohort 1 & $0.531(0.499)$ & $0.315(0.465)$ & $0.407 \quad(0.491)$ & $1.333(1.726)$ & $0.295(0.456)$ \\
\hline Cohort 2 & $0.583(0.493)$ & $0.479(0.500)$ & $0.178 \quad(0.383)$ & $0.981 \quad(1.628)$ & $0.386(0.487)$ \\
\hline \multicolumn{6}{|l|}{ Men } \\
\hline Cohort 1 & $0.740(0.439)$ & $0.451(0.498)$ & $0.390 \quad(0.488)$ & $1.729(1.817)$ & $0.355(0.478)$ \\
\hline Cohort 2 & $0.765(0.424)$ & $0.623(0.485)$ & $0.185 \quad(0.389)$ & $1.164(1.716)$ & $0.470(0.499)$ \\
\hline \multicolumn{6}{|l|}{ Women } \\
\hline Cohort 1 & $0.360(0.480)$ & $0.203(0.402)$ & $0.435(0.496)$ & $1.006(1.573)$ & $0.245(0.430)$ \\
\hline Cohort2 & $0.426(0.495)$ & $0.355(0.479)$ & $0.167(0.373)$ & $0.824(1.530)$ & $0.313(0.464)$ \\
\hline \multicolumn{6}{|l|}{ Men Cohort 1} \\
\hline Family & $0.698(0.459)$ & $0.445(0.497)$ & $0.363(0.481)$ & $1.432(1.645)$ & $0.343(0.475)$ \\
\hline SAL & $0.836(0.370)$ & $0.535(0.499)$ & $0.361(0.481)$ & $1.880(1.700)$ & $0.441 \quad(0.497)$ \\
\hline BS/ENS & $0.823(0.382)$ & $0.791(0.407)$ & $0.039(0.194)$ & $0.209(0.874)$ & $0.050(0.217)$ \\
\hline Independent & $0.864(0.343)$ & $0.622(0.485)$ & $0.279(0.449)$ & $1.738(1.786)$ & $0.451 \quad(0.498)$ \\
\hline Humanitarian & $0.583(0.494)$ & $0.095(0.293)$ & $0.838(0.369)$ & $2.669(1.980)$ & $0.291 \quad(0.455)$ \\
\hline \multicolumn{6}{|l|}{ Men Cohort 2} \\
\hline Family & $0.743(0.437)$ & $0.543(0.499)$ & $0.279(0.445)$ & $1.492(1.986)$ & $0.546(0.498)$ \\
\hline SAL & $0.916(0.278)$ & $0.754(0.432)$ & $0.177(0.382)$ & $1.538(1.787)$ & $0.642(0.480)$ \\
\hline BS/ENS & $0.663(0.473)$ & $0.624(0.485)$ & $0.059(0.236)$ & $0.188(0.848)$ & $0.061 \quad(0.240)$ \\
\hline Independent & $0.885(0.319)$ & $0.801(0.400)$ & $0.095(0.294)$ & $0.953(1.374)$ & $0.469(0.500)$ \\
\hline Humanitarian & $0.264(0.442)$ & $0.060(0.237)$ & $0.774(0.420)$ & $1.098(1.828)$ & $0.314(0.465)$ \\
\hline \multicolumn{6}{|l|}{ Women Cohort 1} \\
\hline Family & $0.323(0.468)$ & $0.182(0.386)$ & $0.438(0.497)$ & $0.874(1.461)$ & $0.232(0.423)$ \\
\hline SAL & $0.499(0.500)$ & $0.277(0.448)$ & $0.444(0.498)$ & $1.391(1.697)$ & $0.325(0.469)$ \\
\hline BS/ENS & $0.335(0.473)$ & $0.300(0.459)$ & $0.105(0.308)$ & $0.316(0.968)$ & $0.100(0.300)$ \\
\hline Independent & $0.529(0.500)$ & $0.364(0.482)$ & $0.313(0.464)$ & $1.137(1.578)$ & $0.318(0.466)$ \\
\hline Humanitarian & $0.224(0.417)$ & $0.025(0.157)$ & $0.887(0.317)$ & $1.323(1.900)$ & $0.201 \quad(0.401)$ \\
\hline \multicolumn{6}{|l|}{ Women Cohort 2} \\
\hline Family & $0.375(0.484)$ & $0.309(0.462)$ & $0.177(0.383)$ & $0.899(1.583)$ & $0.336(0.472)$ \\
\hline SAL & $0.666(0.473)$ & $0.490(0.501)$ & $0.264(0.443)$ & $1.547(1.867)$ & $0.556(0.498)$ \\
\hline BS/ENS & $0.296(0.457)$ & $0.272(0.446)$ & $0.081(0.275)$ & $0.232(0.845)$ & $0.098(0.298)$ \\
\hline Independent & $0.588(0.493)$ & $0.522(0.500)$ & $0.112(0.316)$ & $0.720(1.394)$ & $0.307(0.462)$ \\
\hline Humanitarian & $0.033(0.179)$ & $0.012(0.108)$ & $0.644(0.492)$ & $0.291(1.132)$ & $0.075(0.264)$ \\
\hline
\end{tabular}

${ }^{\mathrm{a}}$ All means are in percents except months unemployed. See Section 4 for variable definitions. 
Table 2: Visa Status, Demographic Characteristics, and Human Capital Endowments LSIA Immigrants by Gender and Cohort (Means ${ }^{\mathrm{a}}$ and Standard Deviations)

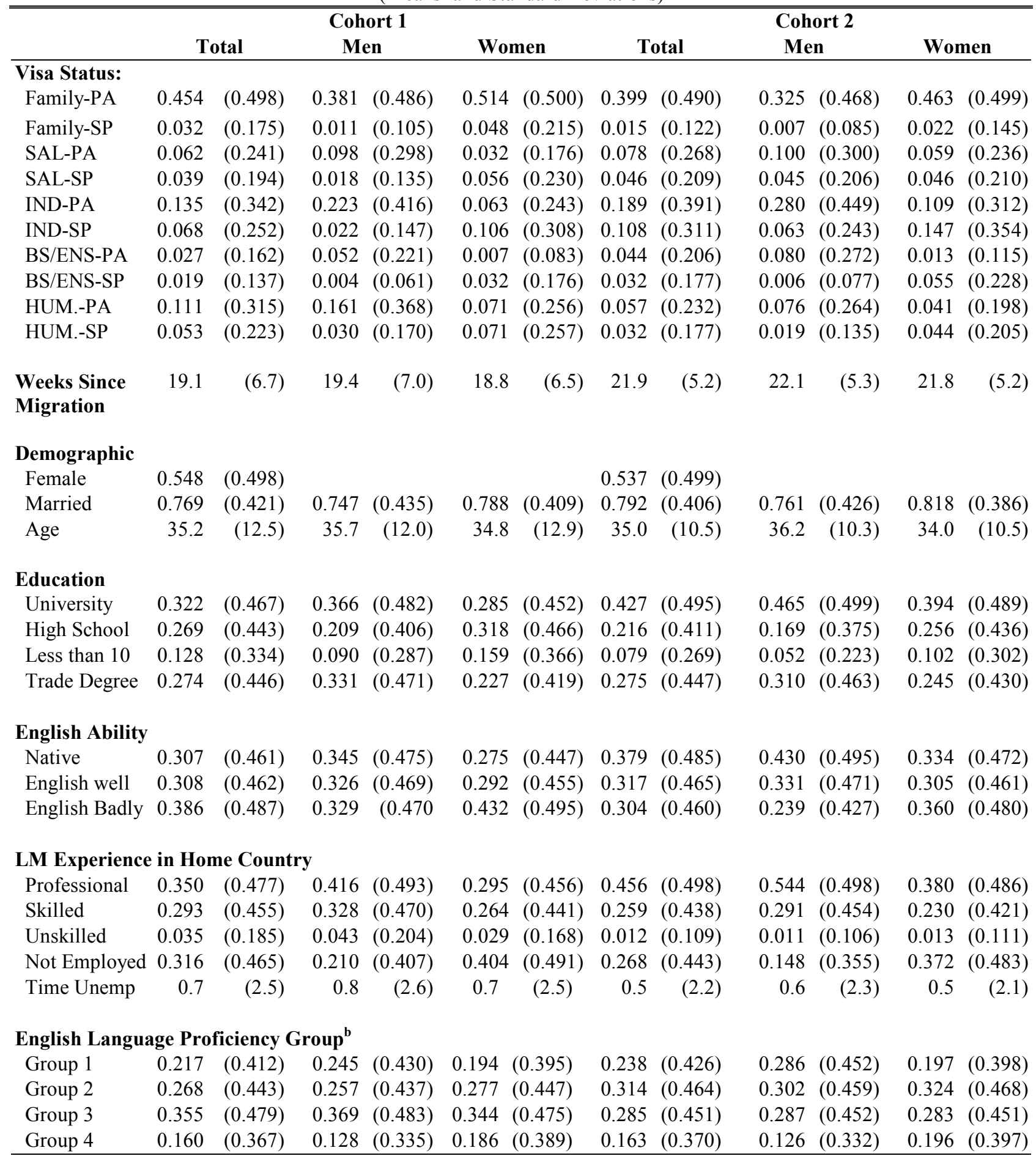

${ }^{\mathrm{a}}$ Means are in percents except for time since migration (weeks), age (years), and time unemployed (months).

${ }^{\mathrm{b}}$ Group 1 is those countries rating 98 percent or higher on the English proficiency index. Group 2 is those countries with a rating of 80 percent or higher, while Group 3 is countries with a rating between 50 percent and 80 percent. Countries with a rating of less than 50 percent make up Group 4 (DIMA, 1999). See Section 4 for other variable definitions. 
Table 3: Determinants ${ }^{\mathrm{a}}$ of Labor Market Participation by Gender and Cohort (Probit Marginal Effects and Standard Errors)

\begin{tabular}{|c|c|c|c|c|c|c|c|c|}
\hline \multirow[b]{3}{*}{ Cohort 2} & \multicolumn{4}{|c|}{ Women } & \multicolumn{4}{|c|}{ Men } \\
\hline & Total & \multirow[t]{2}{*}{ Cohort 1} & \multirow[t]{2}{*}{ Cohort 2} & \multirow[t]{2}{*}{$\begin{array}{l}\text { Significance Level } \\
\text { Cohort } 2 \text { - Cohort } 1^{\text {b }}\end{array}$} & Total & \multirow[t]{2}{*}{ Cohort 1} & \multirow[t]{2}{*}{ Cohort 2} & \multirow[t]{2}{*}{$\begin{array}{l}\text { Significance Level } \\
\text { Cohort } 2 \text { - Cohort } 1^{b}\end{array}$} \\
\hline & $0.070 \quad(2.14)$ & & & & $0.007 \quad(0.28)$ & & & \\
\hline PA Status & $0.156 \quad(4.79)$ & $0.163 \quad(4.10)$ & 0.155 (2.75) & $\mathrm{p}=0.862$ & $0.063 \quad(2.30)$ & $0.074 \quad(2.21)$ & $0.042 \quad(0.95)$ & $\mathrm{p}=0.669$ \\
\hline Visa Status & & & & $\mathrm{p}=0.000$ & & & & $\mathrm{p}=0.000$ \\
\hline Family & $-0.087(-2.07)$ & $-0.111(-2.11)$ & $-0.036(-0.50)$ & & $0.043 \quad(1.67)$ & $-0.003(-0.10)$ & $0.104 \quad(3.01)$ & \\
\hline SAL & 0.107 (3.18) & 0.065 (1.67) & $0.196 \quad(2.88)$ & & $0.077 \quad(3.88)$ & $0.034 \quad(1.44)$ & $0.125 \quad(3.59)$ & \\
\hline Independent & $0.100 \quad(2.82)$ & $0.103 \quad(2.53)$ & 0.127 (1.93) & & $0.051 \quad(2.02)$ & $0.028 \quad(1.02)$ & $0.077 \quad(1.77)$ & \\
\hline Humanitarian & $-0.041(-0.90)$ & $-0.018(-0.35)$ & $-0.321(-4.59)$ & & $-0.012(-0.48)$ & $-0.011(-0.37)$ & $-0.196(-3.52)$ & \\
\hline Wks Since Migr. & $-0.001(-0.70)$ & $-0.001(-0.64)$ & $0.000 \quad(0.03)$ & $p=0.734$ & $0.001 \quad(1.01)$ & $0.002 \quad(1.36)$ & $0.001 \quad(0.33)$ & $p=0.763$ \\
\hline Education & & & & $\mathrm{p}=0.692$ & & & & $\mathrm{p}=0.018$ \\
\hline University & $0.003 \quad(0.09)$ & $-0.006(-0.18)$ & $-0.019(-0.40)$ & & $0.052 \quad(2.80)$ & $0.053 \quad(2.43)$ & $0.023 \quad(0.81)$ & \\
\hline High School & $-0.059(-1.84)$ & $-0.051(-1.34)$ & $-0.118(-2.12)$ & & $0.023 \quad(0.96)$ & $0.054 \quad(2.16)$ & $-0.095(-2.14)$ & \\
\hline Less Than 10 & $0.058 \quad(1.16)$ & $0.030 \quad(0.51)$ & $0.101 \quad(1.10)$ & & $0.097 \quad(4.42)$ & $0.106 \quad(4.15)$ & $0.035 \quad(0.83)$ & \\
\hline Enrolled & $-0.161(-4.47)$ & $-0.151(-3.26)$ & $-0.186(-3.32)$ & & $-0.324(-9.55)$ & $-0.382(-8.97)$ & $-0.217(-4.74)$ & \\
\hline English & & & & $\mathrm{p}=0.461$ & & & & $p=0.172$ \\
\hline Well & $-0.063(-1.70)$ & $-0.080(-1.78)$ & $-0.012(-0.19)$ & & $-0.056(-2.05)$ & $-0.065(-1.99)$ & $-0.051(-1.20)$ & \\
\hline Badly & $-0.294(-6.86)$ & $-0.293(-5.71)$ & $-0.291(-3.80)$ & & $-0.230(-6.43)$ & $-0.269(-6.48)$ & $-0.148(-2.46)$ & \\
\hline LM Experience in & n Home Country & & & $\mathrm{p}=0.062$ & & & & $p=0.752$ \\
\hline Prof. & $0.272(8.50)$ & 0.213 & 0.397 & & $-0.024(-0.92)$ & $-0.020(-0.66)$ & $-0.006(-0.16)$ & \\
\hline Skilled & $0.222 \quad(6.76)$ & $0.177 \quad(4.45)$ & $0.326 \quad(6.20)$ & & $0.035 \quad(1.45)$ & $0.043 \quad(1.52)$ & $0.001 \quad(0.02)$ & \\
\hline Unskilled & $0.291 \quad(4.01)$ & $0.282 \quad(3.25)$ & 0.356 & & $0.045 \quad(1.15)$ & $0.047 \quad(1.05)$ & $0.036 \quad(0.77)$ & \\
\hline Time Unemp. & $0.018 \quad(2.98)$ & $0.017 \quad(2.36)$ & $0.018 \quad(1.95)$ & & $0.001 \quad(0.35)$ & $0.004 \quad(1.09)$ & $0.001 \quad(0.26)$ & \\
\hline $\mathbf{N}$ & 5016 & 3165 & 1851 & $\mathrm{p}=0.000$ & 4633 & 2975 & 1658 & $\mathrm{p}=0.000$ \\
\hline
\end{tabular}


Table 4: Determinants ${ }^{\mathrm{a}}$ of Unemployment Status by Gender and Cohort (Probit Marginal Effects and Standard Errors)

\begin{tabular}{|c|c|c|c|c|c|c|c|c|c|c|}
\hline \multirow[b]{3}{*}{ Cohort 2} & \multicolumn{4}{|c|}{ Women } & \multicolumn{6}{|c|}{ Men } \\
\hline & Total & \multirow[t]{2}{*}{ Cohort 1} & \multirow[t]{2}{*}{ Cohort 2} & \multirow[t]{2}{*}{$\begin{array}{l}\text { Significance Level } \\
\text { Cohort } 2 \text { - Cohort } 1^{b}\end{array}$} & \multicolumn{2}{|c|}{ Total } & \multicolumn{2}{|c|}{ Cohort 1} & Cohort 2 & \multirow[t]{2}{*}{$\begin{array}{l}\text { Significance Level } \\
\text { Cohort } 2 \text { - Cohort } 1^{\text {b }}\end{array}$} \\
\hline & $-0.108(-2.19)$ & & & & -0.024 & $(-0.52)$ & & & & \\
\hline PA Status & $-0.127(-2.68)$ & $-0.192(-3.04)$ & $-0.026(-0.56)$ & $\mathrm{p}=0.191$ & 0.069 & $(2.00)$ & 0.059 & $(1.20)$ & 0.052 & $\mathrm{p}=0.568$ \\
\hline Visa Status & & & & $\mathrm{p}=0.090$ & & & & & & $\mathrm{p}=0.005$ \\
\hline Family & 0.349 & 0.476 & $0.097 \quad(1.59)$ & & 0.474 & $(8.42)$ & 0.551 & $(8.63)$ & 0.355 & \\
\hline SAL & $0.421 \quad(6.81)$ & $0.461 \quad(5.84)$ & 0.219 & & 0.491 & $(9.11)$ & 0.572 & $(9.90)$ & 0.308 & \\
\hline Independent & $0.298 \quad(5.02)$ & 0.422 & 0.061 & & 0.415 & (7.94) & 0.568 & $(9.23)$ & $0.130(2.25)$ & \\
\hline Humanitarian & $0.637 \quad(7.49)$ & $0.610(6.74)$ & $0.578 \quad(3.20)$ & & 0.743 & (13.68) & 0.748 & (13.37) & $0.764(6.91)$ & \\
\hline Wks Since Migr. & $-0.013(-4.16)$ & $-0.012(-2.64)$ & $-0.007(-2.37)$ & $\mathrm{p}=0.819$ & -0.008 & $(-3.44)$ & -0.008 & $(-2.83)$ & $-0.009(-3.44)$ & $\mathrm{p}=0.106$ \\
\hline Education & & & & $\mathrm{p}=0.541$ & & & & & & $\mathrm{p}=0.025$ \\
\hline University & $0.043 \quad(1.10)$ & $0.082 \quad(1.53)$ & $-0.019(-0.51)$ & & 0.089 & $(2.71)$ & 0.136 & $(3.01)$ & 0.005 & \\
\hline High School & $-0.034(-0.69)$ & $-0.008(-0.12)$ & $-0.062(-1.41)$ & & 0.069 & (1.64) & 0.062 & (1.16) & 0.089 & \\
\hline Less Than 10 & $-0.109(-1.57)$ & $-0.132(-1.33)$ & $-0.114(-2.54)$ & & 0.047 & $(0.78)$ & 0.010 & $(0.15)$ & $0.054(0.53)$ & \\
\hline Enrolled & $0.059 \quad(1.12)$ & 0.080 & $0.033 \quad(0.65)$ & & 0.013 & $(0.33)$ & 0.093 & $(1.72)$ & $-0.059(-1.60)$ & \\
\hline English & & & & $\mathrm{p}=0.052$ & & & & & & $\mathrm{p}=0.315$ \\
\hline Well & 0.090 & $0.141 \quad(2.10)$ & $0.018 \quad(0.40)$ & & 0.047 & $(1.25)$ & 0.092 & $(1.80)$ & $-0.009(-0.24)$ & \\
\hline Badly & $0.219 \quad(3.10)$ & 0.342 & $-0.014(-0.21)$ & & 0.132 & $(2.45)$ & 0.197 & $(2.93)$ & $-0.004(-0.06)$ & \\
\hline LM Experience in & n Home Countr & & & $p=0.218$ & & & & & & $\mathrm{p}=0.007$ \\
\hline Prof. & $-0.011(-0.21)$ & $-0.054(-0.77)$ & $0.033 \quad(0.70)$ & & -0.056 & $(-1.22)$ & -0.022 & $(-0.39)$ & $-0.144(-2.34)$ & \\
\hline Skilled & $-0.062(-1.26)$ & $-0.085(-1.17)$ & $-0.006(-0.12)$ & & -0.015 & $(-0.33)$ & 0.018 & $(0.32)$ & $-0.095(-1.83)$ & \\
\hline Unskilled & $-0.085(-0.68)$ & $-0.121(-0.74)$ & $-0.107(-1.74)$ & & 0.078 & $(0.97)$ & 0.197 & $(2.00)$ & $-0.114(-3.11)$ & \\
\hline Time Unemp. & $0.021 \quad(2.71)$ & $0.016(1.60)$ & 0.028 (3.79) & & -0.004 & $(-0.75)$ & 0.001 & $(0.14)$ & $-0.012(-1.76)$ & \\
\hline $\mathbf{N}$ & 1937 & 1214 & 723 & $\mathrm{p}=0.000$ & & 446 & 227 & 74 & 1172 & $\mathrm{p}=0.000$ \\
\hline
\end{tabular}


Table 5: Determinants ${ }^{\mathrm{a}}$ of Weeks Unemployed Since Migration

(OLS Coefficients and Standard Errors)

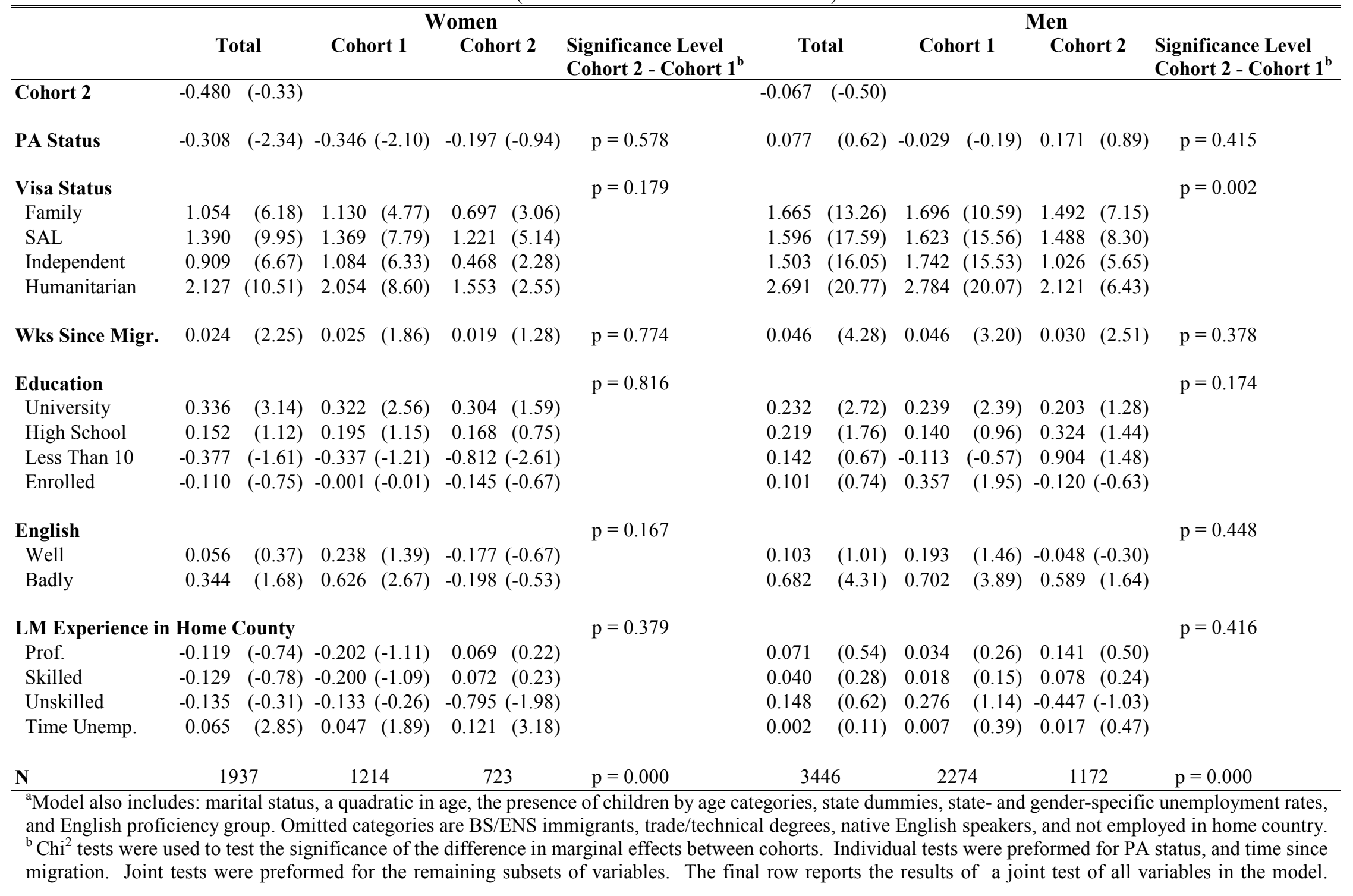


Table 6: Decomposition of Cohort Gap in Labor Market Status and Unemployment Experience

\begin{tabular}{|c|c|c|c|c|}
\hline \multirow[b]{3}{*}{ Labor Market Participation } & \multicolumn{4}{|c|}{ Women } \\
\hline & \multicolumn{2}{|c|}{ Decomposition 1} & \multicolumn{2}{|c|}{ Decomposition 2} \\
\hline & Level & Percent & Level & Percent \\
\hline Difference (Cohort 2 - Cohort1) & 0.052 & & 0.052 & \\
\hline Characteristics & 0.039 & 0.754 & 0.058 & 1.118 \\
\hline Returns & 0.013 & 0.243 & -0.006 & -0.121 \\
\hline \multirow[t]{2}{*}{ Approximation } & \multirow[t]{2}{*}{0.000} & 0.003 & \multirow[t]{2}{*}{0.000} & 0.003 \\
\hline & & 100.0 & & 100.0 \\
\hline Probability of Unemployment & Level & Percent & Level & Percent \\
\hline Difference (Cohort 2 - Cohort 1$)$ & -0.257 & & -0.257 & \\
\hline Characteristics & -0.150 & 0.582 & -0.117 & 0.454 \\
\hline Returns & -0.126 & 0.491 & -0.159 & 0.619 \\
\hline \multirow[t]{2}{*}{ Approximation } & \multirow[t]{2}{*}{0.019} & -0.073 & \multirow[t]{2}{*}{0.019} & -0.073 \\
\hline & & 100.0 & & 100.0 \\
\hline Months of Unemployment & Level & Percent & Level & Percent \\
\hline Difference (Cohort 2 - Cohort 1$)$ & -0.641 & & -0.641 & \\
\hline Characteristics & -0.625 & 0.975 & -0.349 & 0.456 \\
\hline \multirow[t]{4}{*}{ Returns } & \multirow[t]{2}{*}{-0.016} & 0.025 & \multirow[t]{2}{*}{-0.292} & 0.544 \\
\hline & & 100.0 & & 100.0 \\
\hline & \multicolumn{4}{|c|}{ Men } \\
\hline & \multicolumn{2}{|c|}{ Decomposition 1} & \multicolumn{2}{|c|}{ Decomposition 2} \\
\hline Labor Market Participation & Level & Percent & Level & Percent \\
\hline Difference (Cohort 2 - Cohort1) & 0.006 & & 0.006 & \\
\hline Characteristics & -0.010 & -1.855 & -0.047 & -8.489 \\
\hline Returns & 0.016 & 2.857 & 0.052 & 9.491 \\
\hline \multirow[t]{2}{*}{ Approximation } & \multirow[t]{2}{*}{0.000} & -0.002 & \multirow[t]{2}{*}{0.000} & -0.002 \\
\hline & & 100.0 & & 100.0 \\
\hline Probability of Unemployment & Level & Percent & Level & Percent \\
\hline Difference (Cohort 2 - Cohort 1$)$ & -0.197 & & -0.197 & \\
\hline Characteristics & -0.125 & 0.638 & -0.252 & 1.283 \\
\hline Returns & -0.085 & 0.430 & 0.042 & -0.215 \\
\hline \multirow[t]{2}{*}{ Approximation } & \multirow[t]{2}{*}{0.013} & -0.068 & \multirow[t]{2}{*}{0.013} & -0.068 \\
\hline & & 100.0 & & 100.0 \\
\hline Months of Unemployment & Level & Percent & Level & Percent \\
\hline Difference (Cohort 2 - Cohort 1$)$ & -0.689 & & -0.689 & \\
\hline Characteristics & -0.637 & 0.924 & -0.385 & 0.558 \\
\hline \multirow[t]{2}{*}{ Returns } & \multirow[t]{2}{*}{-0.052} & 0.076 & \multirow[t]{2}{*}{-0.304} & 0.442 \\
\hline & & 100.0 & & 100.0 \\
\hline
\end{tabular}


Figure 1

Labor Market Participation

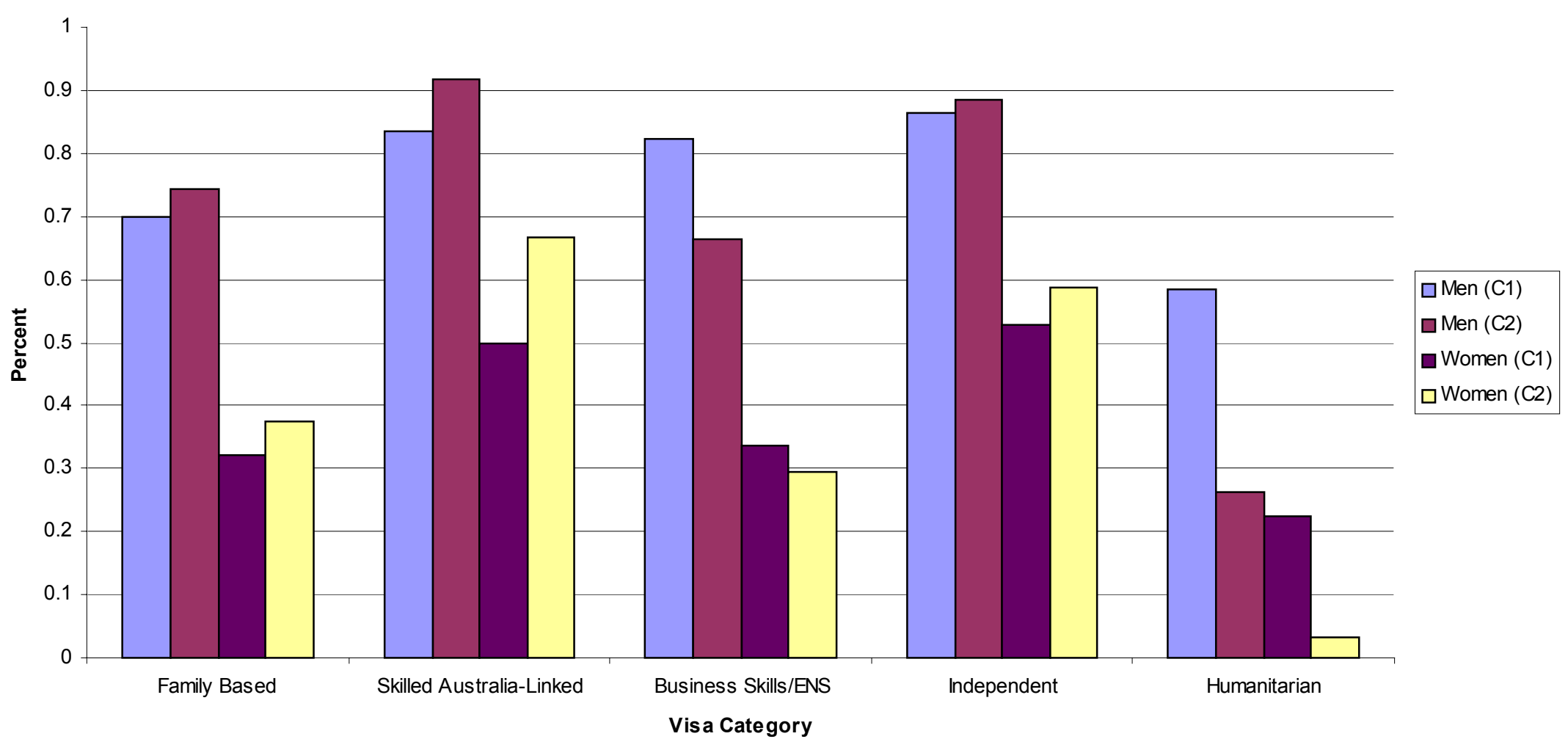


Figure 2

Unemployment Rates

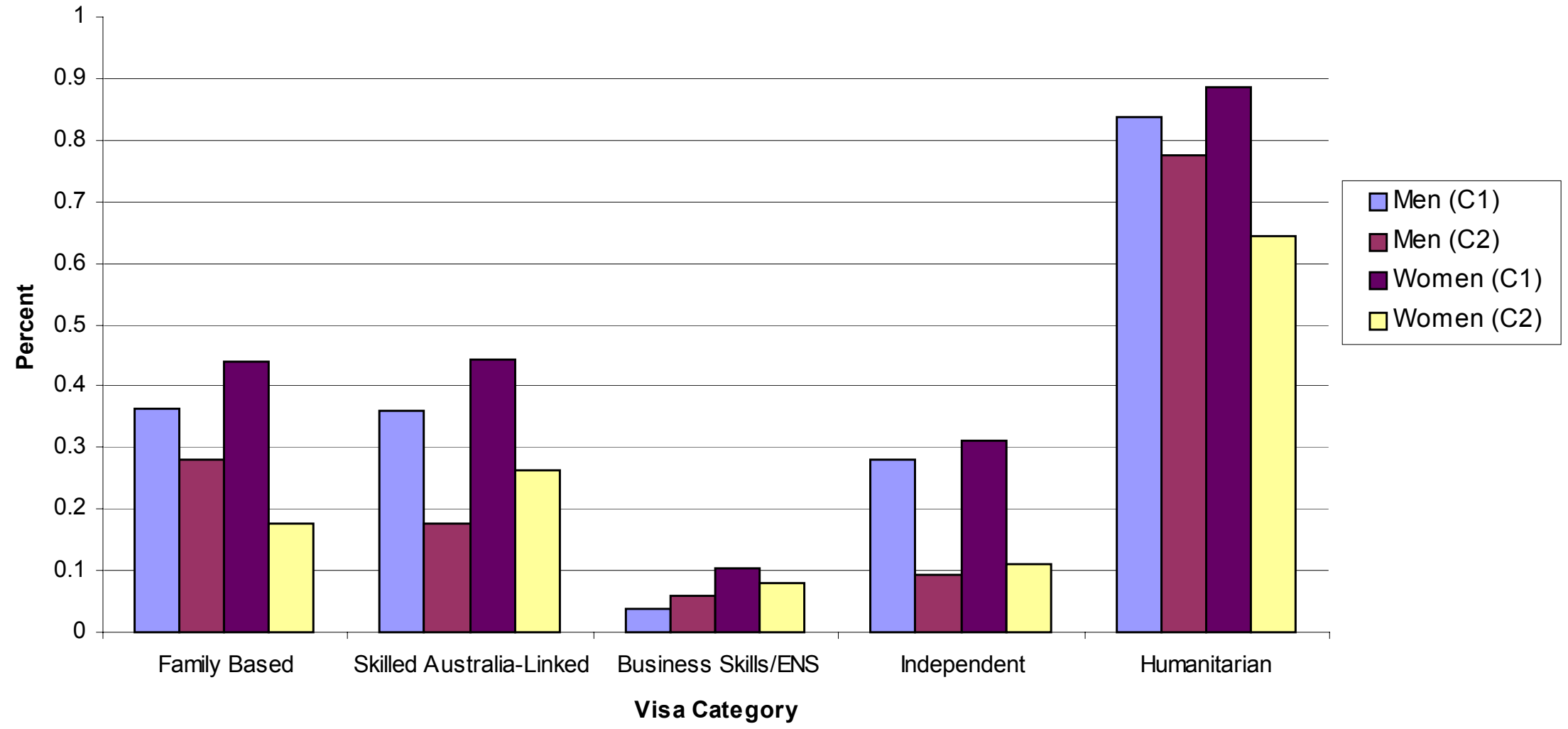


Figure 3

Months Unemployed

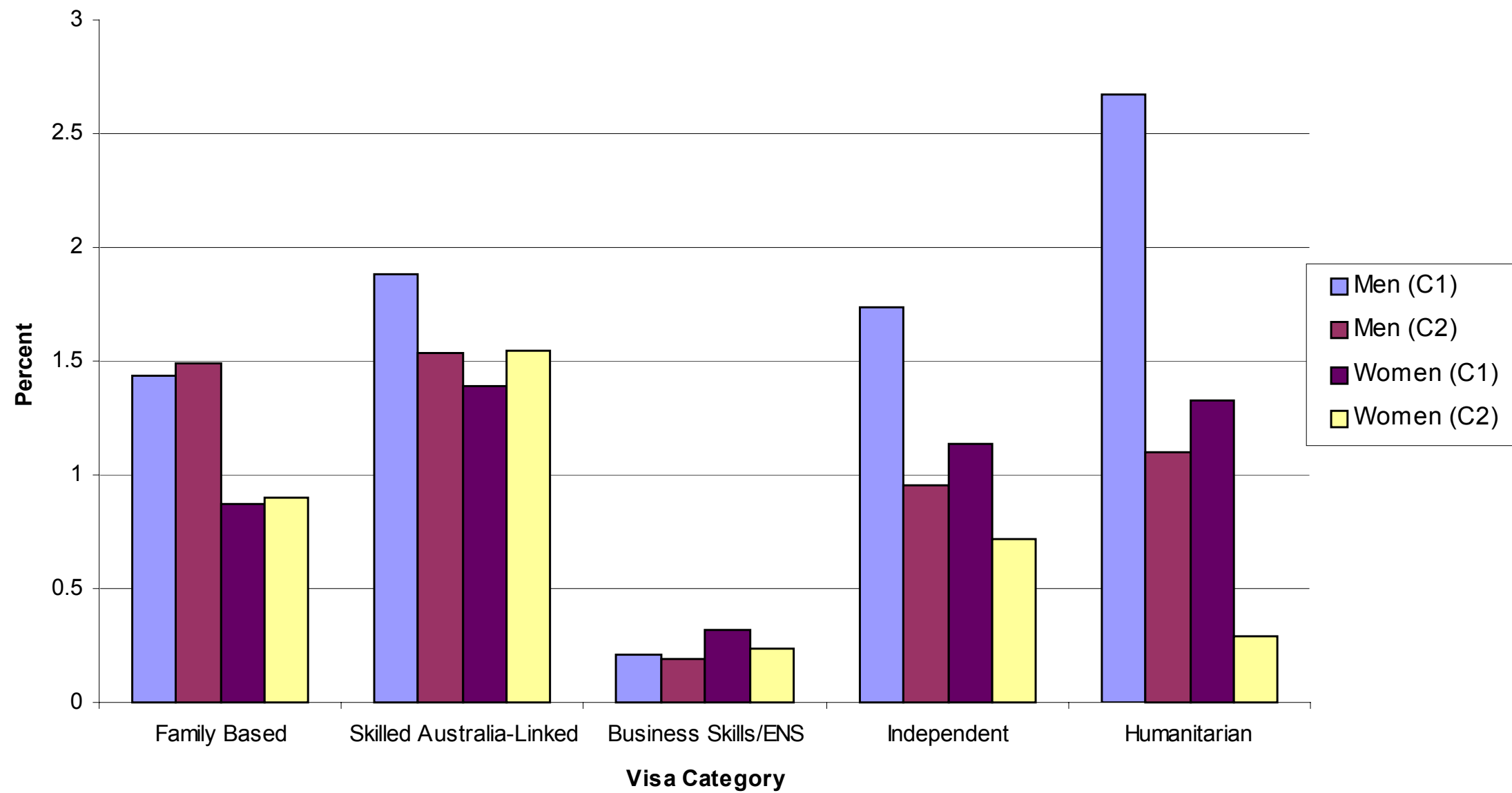




\section{IZA Discussion Papers}

$\begin{array}{ll}\text { No. } & \text { Author(s) } \\ 603 & \begin{array}{l}\text { T. Andrén } \\ \text { B. Gustafsson }\end{array} \\ 604 & \begin{array}{l}\text { S. P. Jenkins } \\ \text { C. Schluter }\end{array} \\ 605 & \text { C. Grund }\end{array}$

606

M. Gerfin

M. Lechner

H. Steiger

607

608

609

610

611

612

613

614

615

616
R. Hujer
U. Blien
M. Caliendo
C. Zeiss

617

618

619

620

Jansen

P. Kuhn

M. Skuterud

W. Koeniger

L. Magee

M. R. Veall

A. L. Booth

G. Zoega

H. Antecol
M. Pannenberg

M. Francesconi

D. A. Cobb-Clark

D. A. Cobb-Clark

Federal Government (1978-1994)

Public Policy and the Labor Market Adjustment
Title

Income Effects from Labor Market Training

Programs in Sweden During the 80's and 90's

The Effect of Family Income during Childhood on Later-Life Attainment: Evidence from Germany

The Wage Policy of Firms - Comparative

Evidence for the U.S. and Germany from

Personnel Data

Does Subsidised Temporary Employment Get the Unemployed Back to Work? An Econometric Analysis of Two Different Schemes

How Do Firms Redline Workers?

5

Economic Aspects of Human Cloning and Reprogenetics

Cognitive Ability and Paternalism

Unemployment Benefits, Risk Aversion, and

Migration Incentives

Some Thoughts on Macroeconomic Fluctuations and the Timing of Labor Market Reform

A Matching Model of Crowding-Out and On-theJob Search (with an Application to Spain)

Internet Job Search and Unemployment

Durations

Long-Term Effects of Unpaid Overtime:

Evidence for West Germany

The Dynamics of Market Insurance, Insurable

Assets, and Wealth Accumulation

Macroeconometric Evaluation of Active Labour

Market Policies in Germany - A Dynamic Panel

Approach Using Regional Data

Allocating Awards Across Noncomparable

Categories

Oligopsony, Institutions and the Efficiency of

General Training

Area

Date

2

$10 / 02$

5

$10 / 02$

5

$10 / 02$

$10 / 02$

$10 / 02$

3

$10 / 02$

3

$10 / 02$

4

$10 / 02$

$10 / 02$

$10 / 02$

2

$10 / 02$

5

$10 / 02$

1

3

$10 / 02$

6

$10 / 02$

The Changing Nature of Employment-Related

5

$10 / 02$

of New Immigrants to Australia

An updated list of IZA Discussion Papers is available on the center's homepage www.iza.org. 